\title{
Unilateral Vulvar Elephantiasis as a Late Complication of Untreated Inguinal Lymphadenitis: a Case Report and Literature Review
}

\author{
Wondimagegnehu Sisay Woldeyes ${ }^{1 *}$ and Dejene Asefa ${ }^{2}$ \\ ${ }^{1}$ Department Obstetrician and Gynecologist, Tercha General Hospital, Ethiopia \\ ${ }^{2}$ Department of Obsteterics and Gynacology, Jimma Univeresty, Ethiopa
}

Submission: March 23, 2017; Published: August 30, 2017

*Corresponding author: Wondimagegnehu Sisay Woldeyes; Obstetrician and Gynecologist, Tercha General Hospital, Ethiopia, Tel: +251-911-907-230; Email: wondmsis400@yahoo.com

\begin{abstract}
When there is disruption of lymphatic flow, protein-rich fluid (lymph) collects in the interstitial space, resulting in lymph edema. The condition may be a subclinical or latent condition where swelling is not evident despite impaired lymphatic transport to a debilitating condition with tropic skin changes such as fat deposits, acanthosis, and warty overgrowths; characteristics of lymph static elephantiasis. Of the total cases of elephantiasis only 1 or $2 \%$ involve the female genitalia and result in Elephantiasis of the female genitalia.

In this report, we present a neglected case of unilateral vulvar elephantiasis in a 55-year old lady as a late complication of untreated inguinal lymphadenitis. In the case of our patient the diagnosed was mainly clinical and she was managed surgically by a wide local excision and reconstruction of the vulva with uneventful postoperative course.

Neglected cases of vulvar lymph edema (elephantiasis) may cause significant mental and physical distress. Definitive diagnosis may be difficult in resource constrained setting, but clinical deduction from patient history, physical findings and local epidemiology may give valuable information towards the possible etiology. When identified, excision and reconstruction has generally a good outcome.
\end{abstract}

\section{Introduction}

When there is disruption of lymphatic flow, protein-rich fluid (lymph) collects in the interstitial space, resulting in lymph edema. This can result either from a congenital and/or inherited condition associated with pathologic development of the lymphatic vessels (primary) or as the result of other conditions (secondary lymph edema). The latter is the most common form, and globally filariasis, due to infection by the nematode Wuscheriabancrofti is responsible for the majority. Other conditions associated with secondary lymph edema includes: malignancies, infections, radiation and lymph node dissection during surgery.

The condition may be a subclinical or latent condition where swelling is not evident despite impaired lymphatic transport to a debilitating condition with tropic skin changes such as fat deposits, acanthosis, and warty overgrowths; characteristics of lymph static elephantiasis [1-3].

Of the total cases of elephantiasis only 1 to $2 \%$ involves the female genitalia and result in Elephantiasis of the female genitalia [2,4]. Though rare, genital elephantiasis, when present is associated with significant physical disability and mental depression [5,6]. It is reported as long term complication of tubercular lymphadenitis, filariasis and sexually transmitted infections in case reports from around the world. In majority of these reports it involved bilateral labia [7,8] From Ethiopia, on the other hand, there is no case report of genital elephantiasis in female. Moreover, the national lymphatic filariasis management and disability prevention guideline discuses only about those cases affecting male genitalia [9]. In contrast, we present a neglected case of unilateral vulvar elephantiasis in a 55-year old lady as a late complication of untreated inguinal lymphadenitis.

\section{Case Presentation}

The patient is 55-year old, para-7 lady from a rural district of southern Ethiopia, with a complaint of mass arising from her genitalia for over the last seven years. Two years prior to noticing the mass, she reports a history of swelling limited to the right inguinal area, with associated pain, fever, night sweating and 
weight loss. The swelling latter burst out following application of herbal medications and hot metal by traditional healers which has later started to produce an offensive discharge and spontaneously healed several months later.

Otherwise it didn't recur and she felt normal until she noted swelling arising from the left side of her external genital area which was progressively increasing over time to attain its current size. When she first noted asymmetry of her external genital area seven years back, she considered it to be as a result of evil spirit and visited almost all traditional healers in the locality where she was treated again with herbal remedies and application of hot metal to the mass and inguinal area and traditional prayers with no avail but losing all her possessions.

With progressive growth of the mass she experienced discomfort during coitus, and later on with all physical activities. Because of its huge size, she ceased committing a penetrative sexual intercourse with her husband as a result; she got divorced by the decision of the local elders which also allowed her husband to marry a new wife. She couldn't attend church, funerals, local markets and her children abandoned her. She states calling the name of her creator God: "... then all my children abandoned me, in fear of evil spirit spreading in the family; I got divorced for the same reason, I lost all my possessions and I didn't know where to go."

Despite all these crippling experiences she stayed at home because, she had no idea that this is a medical condition that can be treated or prevented, until April 2016 (the time of house to house national polio vaccination campaign in the country). During the campaign, besides vaccinating all under five children in the household, health professionals had additional mandate of screening, identifying and registering all women with symptoms of "pelvic organ prolapse". Women with symptoms such as mass per vaginum, urinary and/or bowel complaint and other evidences suggestive of pelvic organ prolapse are transferred to nearby higher institutions, including our hospital for further evaluation and management for free. This patient was accidentally registered and transferred with these women; otherwise she had no intention of visiting a health facility seeking modern health care.

“... there are many women with 'Dolola' (local term used to describe pelvic organ prolapse), including the once arrived with me for treatment, but mine is different." she states. "has it not been for the health extension worker who convinced me to come here, I would have continued living with this crippling experience" she cries cursing the poverty and illiteracy that made her to live with the condition all this time. The patient also received Ivermectin, during mass treatment in the locality.

On general physical examination, the patient entered examination room with unusually wide gait (Figure 1), is a febrile and there was no palpable lymphadenopathy in all accessible areas. On external genital area examination, there is large mass arising from left labia major a, the right labia is normal (Figure
2). The mass is pendulous and hanging down and obstructing the vulvar cleft and measures $45 \mathrm{~cm}$ in length and $25 \mathrm{~cm}$ wide. On standing position, the mass was hanging up to lower $1 / 3^{\text {rd }}$ of her thigh and with the overlying skin being hard, thickened and appearing to have extensive rugosities and hyper pigmentation. Up on palpation the mass was firm, irregular and none pitting and had no tenderness.

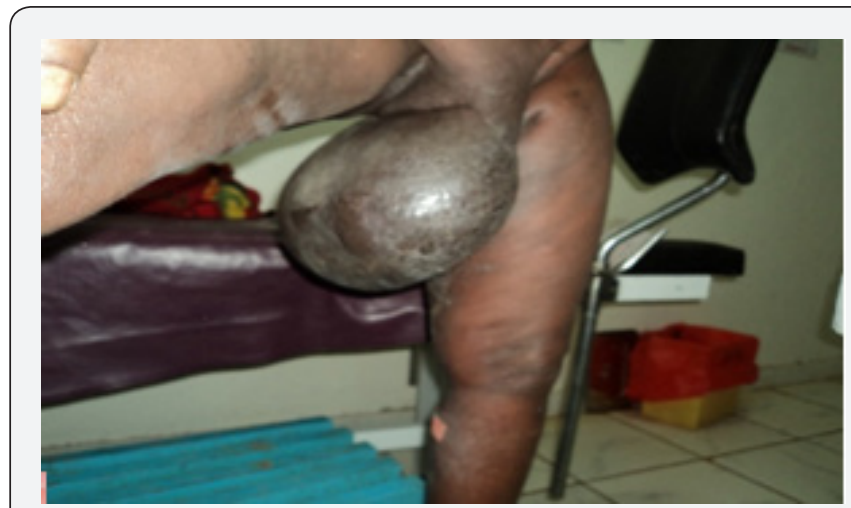

Figure 1: Unusually wide gait resulting from huge vulvar mass

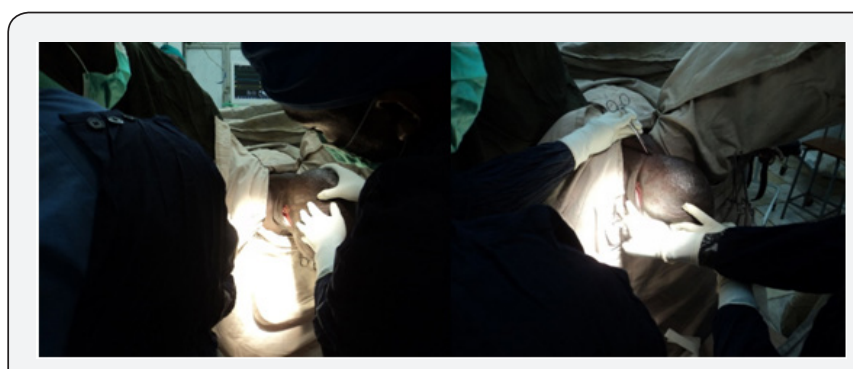

Figure 2: Large growth arising from left labia majora (Between surgeons' hands) (a) the right labia is normal, arrowhead (b).

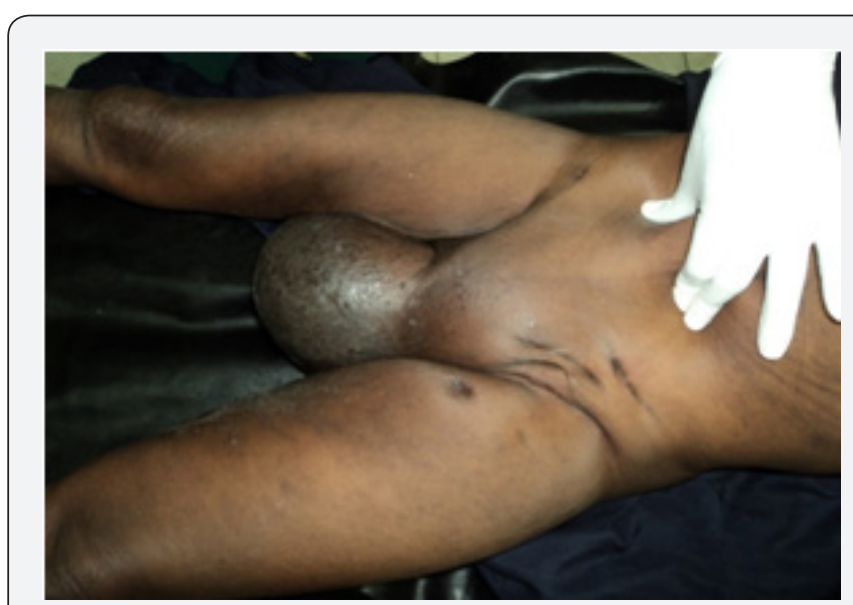

Figure 3: Multiple puckered scars on left inguinal area

No palpable mass or lymphadenopathy noticed in the inguinal areas but there are multiple puckered scars on left inguinal area with no detected draining sinuses (Figure 3). The skins over the inner side of her both thighsis excoriated, hyper-pigmented and thickened with scaling from the chronic irritation by the mass (Figure 4). Neither any abnormality nor 
evidences of active tuberculosis was detected on examination of the other body systems. Chest x-ray, pelvic \&abdominal ultrasound examination, complete blood count and skin snip for onchocerciasis are all negative. FNAC of the mass showed; evidence of chronic inflammation only. Filarial antigen test was not performed (not available in our set-up).

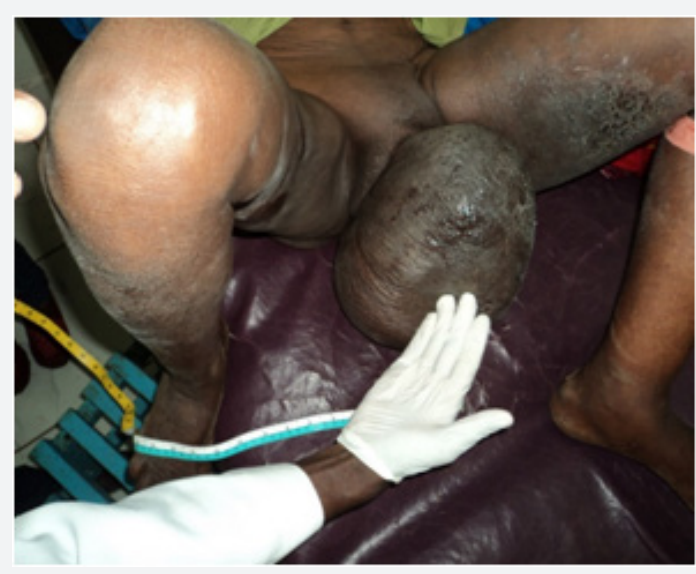

Figure 4: The skin over the left inner thigh is thickened with scaling due to chronic irritation by the mass

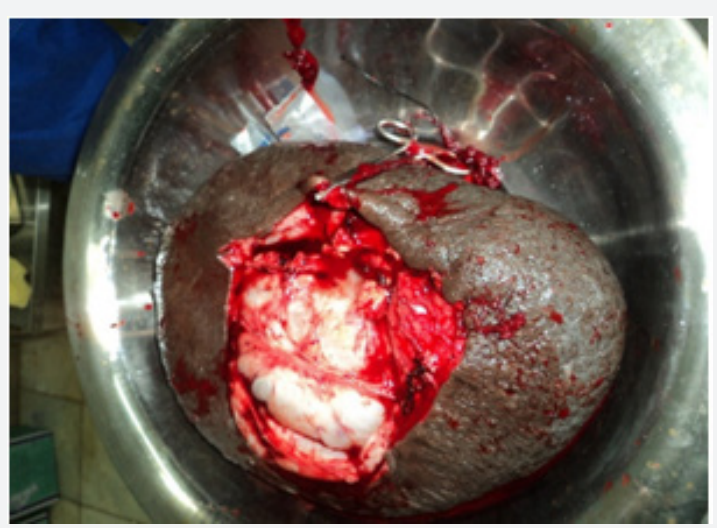

Figure 5: The whole mass excised weighing 6.5killograms from the left labia majora

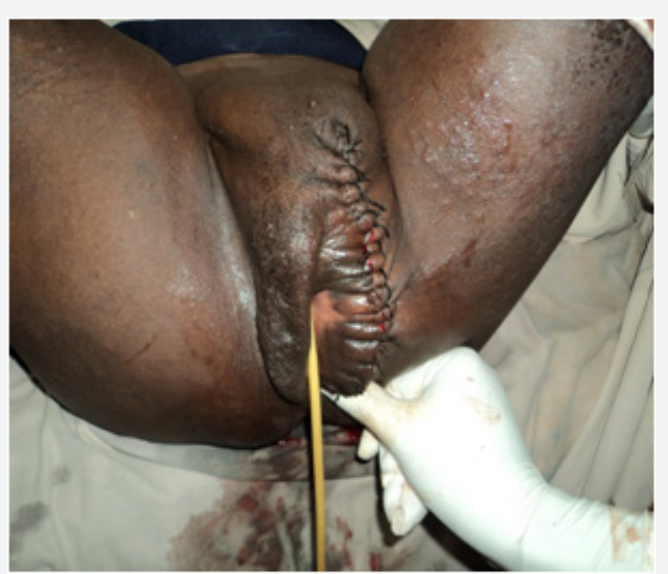

Figure 6: After the vulva is reconstructed with primary closure.
With clinical diagnosis of vulvar elephantiasis, the patient was prepared for surgery after preparing two units of crossmatched blood. Then under spinal anesthesia, the whole mass was excised (total weight of the mass was 6.5 kilograms) (Figure $5)$, the vulva was reconstructed and the skin incision wound was closed primarily (Figure 6). Postoperatively the patient had smooth course and discharged home on her seventh post-op day after removing the skin stitches. Though appointed for follow-up visit after 2 weeks with pathology result, the patient didn't come again.

\section{Discussion}

Lymph edema occurs due to an inability of the existing lymphatic system to accommodate the protein and fluid entering the interstitial compartment at tissue level. Its diagnosis is usually established by history and physical findings of asymmetric measurements and staged clinically using International Society of

\section{Lymphlogy staging}

a. Stage 0 -Stage 0 lymph edema is a subclinical or latent condition where swelling is not evident despite impaired lymphatic transport. Most patients are asymptomatic, but some report a feeling of heaviness in the limb. Stage 0 may exist for months or years before the onset of overt lymph edema occurs (stage I to III).

b. Stage I - Stage I lymph edema is characterized by the accumulation of fluid that subsides with 24-hour limb elevation. The appearance is that of soft edema that may pit, with no evidence of dermal fibrosis. This is sometimes called reversible edema.

c. Stage II - Stage II lymph edema does not resolve with 24hour limb elevation alone. This reflects the evolution of dermal fibrosis. As the fibrosis progresses, the limb may no longer pit on examination. This is sometimes called spontaneously irreversible lymph edema.

d. Stage III - Stage III lymph edema is characterized by lymph static elephantiasis. On exam, pitting is absent, and the skin reveals tropic skin changes such as fat deposits, acanthosis, and warty overgrowths.

Then the severity is described using one of the several classification systems, including the American Physical Therapy Association (APTA) (Mild lymph edema-maximum girth difference $<3 \mathrm{~cm}$, Moderate lymph edema-3 to $5 \mathrm{~cm}$ difference, severe lymph edema - difference $>5 \mathrm{~cm})[1,2]$.

Vulvar elephantiasis following tubercular lymphadenitis, filariasis and lymphogranuloma venerum was described in case reports from different part of the world. Other possible causes of vulvar elephantiasis can be non-filarial infectious or non-infectious at all and they includes; donovanosis, and malignancies, post-radical hysterectomy, lymphadenectomy 
and radiation therapy. Fibro epithelial polyp, fungal infection and granuloma inguinale all make important differentials for this condition. There are also cases in which the cause is not identified after thorough work up [2-5].

In our patient, malignancies, post-radical hysterectomy, lymphadenectomy and radiation therapy are all unlikely causes from the patients' history. Vulvalelepanthiasis following tubercular lymphadenitis on the other hand can be confirmed by past history of diagnosis and treatment for tuberculosis. In addition, evidence of the puckered scars of healed sinuses in the inguinal regions may strengthen our suspicion. In our patient, though no treatment history, the clinical presentation 8-years back, epidemiology, the physical findings (puckered scars), all suggest this possibility.

The other competing differential, lymphogranuloma venerum, can also cause vulvalelepanthiasis as a late complication due to resulting fibrosis in the inguinal area. The major risk factor for this condition, primarily seen in men who have sex with men and those HIV positive people, are absent in our case. However, even in best setups, absence of characteristic clinical presentation, low yield of cultures, and low specificity of serologic assessment make its diagnosis difficult. Despite this, our patients' history, and the fact that she had no high risk sexual exposure makes this possibility less likely compared to TB.

With regard to management of these patients, several case reports are available where good sexual function and cosmoses is achieved after excision and reconstruction, as in our case. We also found a case where recurrence requiring re-excision was reported after several years of such therapy [10].

In general, as limitation, the fact that the patient didn't appear at the beginning for evaluation, and during her current presentation failure to do filarial antigen test and pathological examination of the surgical specimen prevent us from making sound conclusion regarding the underlying cause for the lymphatic distraction and vulvar lymph edema.

In conclusion, inguinal lymphadenitis from various causes can lead to extensive lymph node destruction and vulval lymph edema due to lymphatic obstruction. Neglected cases may cause significant psychosocial and physical distress. Definitive diagnosis may be difficult in resource constrained setting, but clinical deduction from patient history, physical findings and local epidemiology may give valuable information towards possible etiology and other causes of vulvar mass. When identified, excision and reconstruction has generally good outcome.

\section{Acknowledgment}

The authors thank the client for giving her consent to publish her disease condition using the pictures too and Tercha general Hospital for allowing publishing this case report.

\section{References}

1. http://www.uptodate.com/contents/

2. Mohan H, Kundu R, Arora K, Punia RS, Huria A (2014) Spectrum of vulvar lesions: a clinicopathologic study of 170 cases. Int J Reprod Contracept Obstet Gynecol 3(1): 175-180.

3. Mohan H, Bisht B, Goel P, Garg G (2012) Vulval elephantiasis: a case report, hindawi publishing corporation. Case Reports in Infectious Diseases 2012: 3 .

4. Chintamani, JP Singh, Megha Tandon, Rohan Khandelwal, Tushar Aeron, et al. (2010) Vulval elephantiasis as a result of tubercular lymphadenitis: two case reports and a review of the literature. Journal of Medical Case Reports 4: 369.

5. Anjali Sethi, Deepak Sethi (2014) Huge Vulval Elephantiasis of Unknown Aetiology. Journal of Evolution of Medical and Dental Sciences 3(13): 3324-3329.

6. Mwampagatwa H, Alex Ernest (2015) Bilateral giant mysterious vulva tumor in an adolescent: a rare clinical condition and its diagnostic challenges in resource constrained facilities. Sch J App Med Sci 3(1C):148-152.

7. Ipyana HM, Bonaventura CTM, Januarius H (2014) Vulvar filarial elephantiasis in a tanzanian woman; rare presentation of lymphatic filariasis: a case report and a review of literature, Sudan. JMS 9(4).

8. Richens J (2004) Genital manifestations of tropical diseases. Sex Transm Infect 80(1): 12-17.

9. Federal Democratic Republic of Ethiopia, Ministry of health, lymphatic filariasis and podoconiosis morbidity management and disability prevention guideline, February 2016.

10. Muralidhar L, G SK, Venkatesh S (2014) Recurrent Unilateral Vulval Elephantiasis: A Case Report. J Family Reprod Health 8(2): 87-89.

This work is licensed under Creative Commons Attribution 4.0 Licens DOI: $10.19080 / J G W H .2017 .06 .555696$
Your next submission with Juniper Publishers will reach you the below assets

- Quality Editorial service

- Swift Peer Review

- Reprints availability

- E-prints Service

- Manuscript Podcast for convenient understanding

- Global attainment for your research

- Manuscript accessibility in different formats

( Pdf, E-pub, Full Text, Audio)

- Unceasing customer service

Track the below URL for one-step submission https://juniperpublishers.com/online-submission.php 